\title{
Acute Flaccid Myelitis in a Korean Adult
}

\section{Neuroscience}

(A) Check for updates

\section{Du Hwan Kim iD}
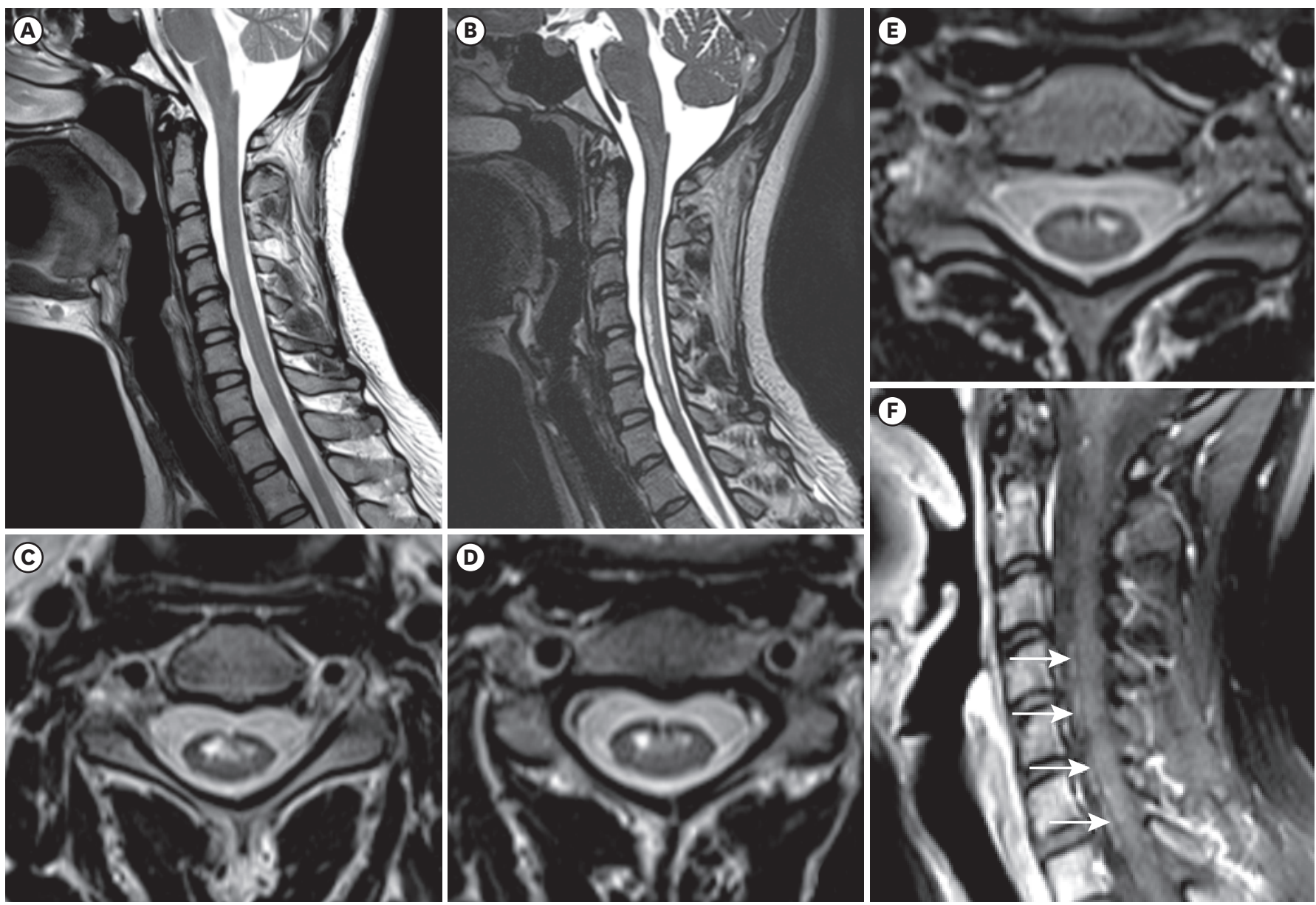

Fig. 1. MRI findings. (A) MRI scans within three hours of symptom onset revealed no definite abnormalities in cervical cord. (B) At 2 weeks after the onset of neurological symptoms, cervical spine MRI revealed T2-hyperintensity within the anterior spinal cord. (C-E) Axial T2 weighted image revealed prominent anterior horn cell involvement at C4 and 5 level on right and C6 level on left. (F) Gadolinium-enhanced T1 weighted image showed ventral root enhancement over C4-7 vertebral levels on paracentral area (arrows). $\mathrm{MRI}=$ magnetic resonance imaging.

Received: Jun 6, 2018

Accepted: Nov 1, 2018 
Address for Correspondence: Du Hwan Kim, MD, PhD

Department of Rehabilitation Medicine, Dongsan Medical Center, School of Medicine, Keimyung University, 56 Dalseong-ro, Jung-gu, Daegu 41931, Republic of Korea.

E-mail: ripheonix@dsmc.or.kr

c) 2019 The Korean Academy of Medical Sciences.

This is an Open Access article distributed under the terms of the Creative Commons Attribution Non-Commercial License (https:// creativecommons.org/licenses/by-nc/4.0/) which permits unrestricted non-commercial use, distribution, and reproduction in any medium, provided the original work is properly cited.

ORCID iDs

Du Hwan Kim (iD)

https://orcid.org/0000-0002-9980-8549

Disclosure

The author has no potential conflicts of interest to disclose.
A previously healthy 28-year-old woman presented with one-day history of sudden onset quadriparesis. Two weeks earlier, she had severe gastrointestinal symptoms of vomiting and diarrhea and a fever as high as $38.3^{\circ} \mathrm{C}$. Cervical spine magnetic resonance imaging (MRI) at three hours of symptom onset revealed no definite abnormal findings (Fig. 1A). Neurologic examination revealed that the weakness of the right arm was overall profound ( 1 or 2 on Medical Research Council [MRC] scale), but the distal weakness (1 or 2 on MRC scale) of the left arm was more severe than the proximal one ( 2 or 3 on MRC scale). Her reflexes were absent in upper limbs. There was no evidence of a sensory deficit and voiding difficulty.

Cerebrospinal fluid (CSF) study revealed mild pleocytosis $\left(12 / \mathrm{mm}^{3}\right)$ and proteins were in the normal range. CSF samples for common neurotropic virus were negative as determined using polymerase chain reaction. Results for antiganglioside antibodies and aquaporin-4 immunoglobulin $\mathrm{G}$ antibodies were negative. A nerve conduction study at 3 days revealed normal sensory nerve conduction and decreased motor nerve conduction amplitude. She was presumptively diagnosed with Guillain-Barré syndrome (GBS) and was treated with 5 days of intravenous immunoglobulin (IVIG). Before the IVIG treatment, neurologic reevaluation demonstrated that the weakness of the right $\mathrm{C} 5$ myotome and the left $\mathrm{C} 7$ or 8 myotome was more marked than other myotomes.

Seven days after IVIG treatment, her arm weakness was markedly improved. Contrary to initial evaluation, DTRs in the upper limb were brisk. Owing to unusual recovery of brisk DTRs, cervical spine MRI was re-examined. MRI showed T2 hyperintensity in the anterior cord between $\mathrm{C} 3$ and $\mathrm{C} 7$ with ventral root enhancement (Fig. 1B-F). Considering acute upper limb paralysis with involvement of the anterior horn cell and ventral root enhancement on MRI, a diagnosis of acute flaccid myelitis (AFM) was made. Intravenous methylprednisolone $(1 \mathrm{~g} /$ day $)$ was administrated for 5 days. Two years later, strength improved to near normal, but asymmetric weakness of $\mathrm{C} 5$ myotome on right and $\mathrm{C} 7$ myotome on left remained.

AFM is a rare myelitis subtype characterized by acute flaccid paralysis owing to spinal cord gray matter involvement of unknown etiology. ${ }^{1}$ Several states in the United States (California, Colorado, and Utah) reported outbreaks of AFM from 2012 to 2015.1-3 This garnered global attention to AFM because of the fear of polio recurrence. In 2015, the US Council of State and Territorial Epidemiologists defined AFM as persons of any age with onset of acute focal limb weakness (prerequisite) and either: 1) MRI with spinal cord lesion largely restricted to gray matter spanning one or more spinal segments (confirmed case) or 2) CSF pleocytosis of $>5$ white blood cell $(\mathrm{WBC}) / \mathrm{mm}^{3}$ (probable case) ${ }^{4}$ Additionally, idiopathic acute transverse myelitis, spinal cord ischemia, GBS, neuromyelitis optica spectrum disorders and multiple sclerosis should be ruled out per the established criteria. To our knowledge, there have been no reports of AFM in a Korean adult.

\section{REFERENCES}

1. Messacar K, Schreiner TL, Van Haren K, Yang M, Glaser CA, Tyler KL, et al. Acute flaccid myelitis: a clinical review of US cases 2012-2015. Ann Neurol 2016;80(3):326-38. PUBMED | CROSSREF

2. Van Haren K, Ayscue P, Waubant E, Clayton A, Sheriff H, Yagi S, et al. Acute flaccid myelitis of unknown etiology in California, 2012-2015. JAMA 2015;314(24):2663-71. PUBMED | CROSSREF 
3. Maloney JA, Mirsky DM, Messacar K, Dominguez SR, Schreiner T, Stence NV. MRI findings in children with acute flaccid paralysis and cranial nerve dysfunction occurring during the 2014 enterovirus D68 outbreak. AJNR Am J Neuroradiol 2015;36(2):245-50. PUBMED | CROSSREF

4. Council of State and Territorial Epidemiologists. Standardized Case Definition for Acute Flaccid Myelitis. Atlanta, GA: Council of State and Territorial Epidemiologists; 2015. 